\title{
GENDER REPRESENTATION IN ENGLISH AS AFOREIGN LANGUAGE (EFL) TEXTBOOKS FOR SENIOR HIGH SCHOOL IN INDONESIA
}

\author{
Puput Arfiandhani \\ Universitas Muhammadiyah Yogyakarta, Indonesia
}

\begin{abstract}
English language textbooks, as one of the manifestations of language-ineducation policy, played an important role to connect classroom language and real world language. The present study investigates the gender representation in the English as A Foreign Language (EFL) textbooks. The analysis is done by tallying the number of occurrence of male and female characters. The research results indicated that there is an equitable representation of both males and females. However, there is a gender bias portraying females. Males are portrayed to be more authoritative and put in the spotlight, such as the one of doing the networking in business meeting while female characters are in the background, doing presentation, giving speech, more representative in politics, in which females are absent on this spotlight.
\end{abstract}

Key words: gender representation, EFL textbooks, Senior High School

\section{INTRODUCTION}

Promoting gender equality is important to ensure equal opportunities for both men and women to have equal opportunities in the society. As one of keys for achieving social justice, gender equality has been promoted, and discussed within various fields, including in the field of language-in-education.

English language textbooks, as one of the manifestations of language-in-education policy,play animportant role to connect classroom language and real world language. According to Sadker and Zittleman (as cited in Blumberg, 2009), textbooks are used 80 to $95 \%$ of classroom time, either literally or inspiring teachers' instructional practices. Often, along with teachers, it becomes the only means for students to get direct access to the target language. It is especially true in the context of English as a Foreign Language (EFL) learning in Indonesia where students are exposed with English language use is only in the classrooms and they rarely can authentically practice the language outside of the classrooms.

Related to the context of authenticity in textbooks, some writers have posed the issue of gender representation due to the fact that it constructs how people socially behave. As mentioned by Law and Chan (as cited in Yang, 2011), gender stereotypes are formed through the socialization process, which includes classroom interaction and materials. This is in line with Celce-Murcia's (as cited in Shehadeh, 1999) that gender stereotyping can be either socially constructed or biologically determined. Thus, textbooks as parts of education are also a means to promote societal norms.

Within the context of Indonesia, two studies have been done to examine gender portrayals in the prescribed EFL textbooks in Indonesia. The first study, Ariyanto's (2018) examined the gender portrayal in junior high school textbooks. The second one, Budiyanto's (2018) investigation was on senior high school textbooks. Both studies 
showed that Indonesian EFL textbooks still depicts gender bias in their portrayal of both gender.

Similar with both previous studies, the present study aims at finding out the gender representation in three textbooks for senior high school students, i.e. textbook for Grade X, XI and XII. The textbooks are endorsed by the Ministry of Education and Culture and used in senior high schools throughout Indonesia. While both studies employed Critical Discourse analysis in looking at the data, the present study looked at the proportion of male and female characters as well as their domestic and occupational roles as presented in the textbooks. The present study aims at investigating the proportion of male and female characters as well as their domestic and occupational roles as presented in the textbooks.

\section{Gender in Education}

The issue with gender bias in educational setting is that it may prevent students from getting involved in maximum potential learning opportunities. In educational setting, as cited in Cameron (2005), Baxter's (2003) study on boys and girls' contribution to group discussion in an English class showed that teachers already had a set of notions and expectations of girls and boys' behavior. Boys were perceived to be more assertive and to 'take command' to the group, while girls were perceived to be collaborative, and sensitive in listening to the group discussions. If both genders went to the extreme of those behavioral expectations, they tended to be less rewarded. Interestingly, boys who flout their behavioural expectations (showing more sensitivity and collaborativeness) tend to be better rewarded. However, girls who showed masculine behaviour (assertiveness and authority) were not favoured. This created a discrepancy in both genders' effectiveness and equal contributions in the discussions.

One of the possible means to diminish the perception discrepancy is through careful control in education. Law and Chan (2004) suggested that people's internalized stereotypical differences were formed in various social activities they are involved in, including schools. Schools could therefore be places to internalize fairer societal norms and values, including gender equality. Persil et al. (2006) suggested that education might be an important socializing institution to diminish gender bias. Thus, bringing the issue of gender bias in education into the spotlight could help to identify this problem as well as to better formulate action to be integrated into education to diminish gender bias.

Identification is an important step to further action towards gender equality in education. Cameron (2005) mentioned that while gender hierarchy has not been eliminated, it is no longer the same as in the 1970s. Today, there is more commonness shared by both genders, be it sports preferences, fashion style, or any other interests that used to be more stereotypically defined. Thus, the awareness of this hierarchy differences and commonness in society is needed to help providing a fairer classroom environment. Shehadeh (1999) suggested that it is important for teachers to be more aware of the issue of gender bias in textbooks so that they can better design their teaching and classroom activities which can still facilitate both genders appropriately. One particular and prevalent area might be the use of textbooks. Classrooms activities and materials, which can promote equal opportunities, would be developed and promoted for more effectiveness of educational process in language classrooms. 
Since language and gender affects each other, the use of language in educational contexts, is both affected and affecting the construct of gender. When the problem of gender bias takes place, this reflects and affects how gender is represented and constructed in the society. Sunderland (2006: 40) stated that the understanding of the reasons that motivate the language used is important in providing information about the context in which the language is performed. Thus, studying how language is used reflects the textbook authors' and society's belief to some extent as well as evaluation on whether any misrepresentation exists.

\section{Language and Gender}

Issues on language and gender have drawn a lot of research interests. The relationship between language and gender was put into the spotlight when Robin Lakoff (1975), in Language and Women's Place, mentioned that in patriarchal society women's language is the representation of powerlessness, triviality and insecurity. On this notion, it is interesting to explore more on how languages used may represent people's behavior or vice versa.

Some researches suggest that languages used contribute to how people behave. Tannen (as citedin Cameron, 2005) suggested that linguistic gender differences happen because people tend to engage more in the same-gender groups. Additionally, Cameron (2005) pointed out that the relationship of language and gender is based on what activities women and men participate in. The different activities require the use of different registers as well as communication strategies. When females are engaged in casual chatting and males in sports activities, the register used and the communication strategy used are different from each other. From these perspectives, language use is affected by what kind of activities men and women are involved in and people's interaction with each other. As asserted by Sunderland (2000), while identity will not be determined by what kind of language and how the language is used and gender is represented in the society, it will shape their identity.

On the other hand, languages used reflect people's identity, including gender. To pretend to have a particular identity, one can modify the way they use their language. On how language represents gender, Hall (as cited in Cameron, 2005) investigated sex-phone workers in west coast areas in the U. S. The result showed that people from various ethnicities and genders modified their language to be perceived to have different identity. A male phone sex worker modified his languages so that callers thought he was a female. Language apparently is a representation of people's social identity.

The relationship between language and gender can work two ways, in which they both affect each other. As suggested by Cameron (2005), gender traits, which include language, are inflecting and inflected by one's societal identity dimensions, such as age, ethnicity, class, and occupation among others. According to Sunderland (2000), in any context, including in educational setting, perception and expectation towards students are realized through gendered language.

\section{Gender Representation in Textbooks}

Gender bias still exists in textbooks in many contexts. A research conducted by Xiaoping (2004) revealed that gender bias existed in three English reading textbooks in China in which the accumulative numbers from three reading books of male's appearance $(73 \%)$ significantly outnumbered that of female $(27 \%)$. In terms of occupational roles, 
not all characters' occupation was mentioned, but when it was, there was a sharp difference. Males' occupation was mentioned $84 \%$ while females' was mentioned 16\% of the whole occupational roles. In English language textbooks for Malaysian secondary school students, a textbooks content analysis by Mukundan and Nimehchisalem (2008) indicated that the textbooks contained gender bias in which males were portrayed to have negative characters $(93 \%)$ such as being aggressive, breaking rules, being disorganized and cruel to animals, more than females $(7 \%)$ whose negative characters were being talkative, wasteful, and breaking rules. Ariyanto's (2018) critical discourse analysis on visual and verbal texts in an Indonesian Junior High School textbook for Grade VII indicated that the textbook portrayed gender bias. Female characters tend to be stereotypically portrayed as more passive and less dominant than their male counterparts. Those researches showed that gender bias exists in many contexts, including in Indonesian EFL textbooks, and both males and females could be at a disadvantage.

The bulk of research on gender representation in EFL textbooks signifies the need to conduct research on looking at gender representation in EFL textbooks which are currently used.The present study investigates the gender representation in the nationally endorsed EFL textbooks for senior high school students (Grade 10, 11 and 12). To figure out how gender is represented in those textbooks, the number of characters, the domestic and occupational roles, and the number of utterances made are investigated. The results of those three categories of male and female characters are then compared.

\section{METHODS}

To find out if gender bias exists in the EFL textbooks for Senior High School students in Indonesia, a model of analysis done by Yang (2011) was used. In her model of analysis, a tally was done to count the appearance of each gender in the textbooks. However, due to time limitation, only three out of six aspects were analyzed. These three aspects are male and female characters in illustration and texts, domestic and occupational roles, and utterances made. Three aspects that are excluded are lexical and physical representations of male and female characters, range of activities performed and frequency of male/female firstness within single phrases. The analysis process was done as follows.

Male and Female Characters in Visual and Verbal Texts. A counting on the frequency of appearance of male and female characters both in pictures (visual texts) or dialogues and stories (verbal texts) was done. In cases where the gender of the characters in the visual or verbal texts is not easily identified, then, the gender is decided based on the name and pronouns used. However, in the cases where no other clues of the characters are available, then it is left out of the counting.

Utterances Made by Male and Female Characters. The analysis is done through counting the utterances made by male and female characters both in visual and verbal texts. In deciding whether the interlocutors in the text are either male or female, the character's name, pronoun addressing system and or illustration is observed. In cases where the character's gender is unclear or not mentioned, then it is leaved out of the counting.

Domestic and Occupational Roles of Male and Female Characters. The analysis is done through deciding their domestic roles (e.g. father, mother, brother, and sister) or occupations in visual and verbal texts. 


\section{RESEARCH FINDINGS}

\section{Male and Female Characters in Visual and Verbal Texts}

The number of male and female characters in visual and verbal texts is counted by tallying the occurrence of male and female characters in illustrations and dialogues in the textbook for each grade. The proportion of male and female characters tends to be equitable. In the EFL textbook for Grade 10, with the occurrence of 91times $(52.30 \%)$, male character outnumbers the occurrences of female characters that appear83times $(47.70 \%)$. Similarly, there is also an equal representativeness of the number of male and female students in EFL textbooks for Grade 11. Both male and female characters appear for 28 times $(50 \%)$ each. The relatively equal proportion of male and female characters can also be found in EFL textbooks for Grade 12. The male character appears for 79 times $(46.75 \%)$ and the female characters appear for 90 times $(53.25 \%)$ in the textbook.

For the illustrations, the gender was determined by observing the style of hair, clothing, and make up. Meanwhile, for the dialogues, the gender of the characters was determined by the name of those involved in the dialogue, the character, which represents and model the dialogues, and the way they address each other in character (using Sir, Miss, or Indonesian addressing system of Pak (literally translated as 'Father') and Bu (literally translated as 'Mother' - a way to address significantly older people). However, there is one character that is unidentifiable (Grade 11, Page 11, Dialogue 1). It is due to the fact the there is no name of the character, the addressing system, as well as picture. Thus, it is left out for the sake of analysis.From these numbers, it can be concluded that there is no bias in terms of male and female characters number representation. The details can be summed up in the table below:

Table 1. The number and frequency of male/female characters represented in illustrations and dialogues

\begin{tabular}{lll}
\hline Grade & Male Characters & Female Characters \\
\hline $\mathbf{1 0}$ & $91(52.30 \%)$ & $83(47.70 \%)$ \\
$\mathbf{1 1}$ & $28(50.00 \%)$ & $28(50.00 \%)$ \\
$\mathbf{1 2}$ & $79(46.75 \%)$ & $90(53.25 \%)$ \\
\hline
\end{tabular}

\section{Utterances Made by Male and Female Characters}

There is an equal representation of male and female in terms of utterances they produced as can be found in Table 4. In the textbook for Grade 10, males made 99 utterances $(46.26 \%)$ in which females made $115(53,74 \%)$ utterances. Meanwhile, in the textbook for Grade 11, males outnumber that of females. Males made 127 (53.14\%) utterances while females made 112 (46.86\%) utterances.

In terms of turns in single-gender dialogues, the number of turns in both textbooks outnumbers females as presented in Table 5 and Table 6 . In the textbook for Grade 10, males made 16 turns, in contrast to female with 4 turns. The steep differences were more apparent in textbook for Grade 11. While males made 9 turns, there was no female-only dialogue to be found. But, this seemingly obvious gender bias was made up in mixed gender dialogues. In the textbook for Grade 10, females made 37 turns while males only 
19 turns. Meanwhile, in the textbook for Grade 11, females made 70 turns while males made 61 turns.

Table 2. The number of male/female utterances

\begin{tabular}{lll}
\hline Grade & Male Utterances & Female Utterances \\
\hline $\mathbf{1 0}$ & $151(48.87 \%)$ & $158(51.13 \%)$ \\
$\mathbf{1 1}$ & $98(47.57 \%)$ & $108(52.43 \%)$ \\
$\mathbf{1 2}$ & $79(50.00 \%)$ & $79(50.00 \%)$ \\
\hline
\end{tabular}

Domestic and Occupational Roles of Male and Female Characters

Table 4. Domestic and occupational roles of male and female characters in Grade XI Textbook

Domestic and Occupational Roles of Male and Female Characters

\begin{tabular}{cccc}
\hline Male & Number & Roles & Number \\
\hline Unidentified & 14 & Unidentified & 16 \\
Fisherman & 5 & Wife & 5 \\
President & 3 & Costumer & 5 \\
Customer & 2 & Concierge & 1 \\
Company Director & 2 & Student & 1 \\
Store Attendant & 1 & & \\
Student & 1 & & $\mathbf{2 8}$ \\
\hline Total Number & $\mathbf{2 8}$ & Total Number & \\
\hline
\end{tabular}

Table 5. Domestic and occupational roles of male and female characters in Grade XII Textbook

Domestic and Occupational Roles of Male and Female Characters

\begin{tabular}{ccccc}
\hline & Male & Number & Roles & Female \\
Roles & 37 & Student & Number \\
Student & 17 & Teacher & 43 \\
Teacher & 7 & Unidentified & 24 \\
Politician & 2 & Politician & 6 \\
Policeman & 2 & Buyer & 4 \\
Bike Rider & & & 3 \\
\hline
\end{tabular}




\begin{tabular}{|c|c|c|c|}
\hline Staff & 2 & Galey Attendant & 3 \\
\hline Manager & 2 & Staff & 2 \\
\hline Unidentified & 2 & Bookshop Customer & 1 \\
\hline Seller & 1 & Laboratory Attendant & 1 \\
\hline Gallery Attendant & 1 & Mother & 1 \\
\hline Bookshop Attendant & 1 & Daughter & 1 \\
\hline Laboratory Attendant & 1 & Sibling & 1 \\
\hline Father & 1 & & \\
\hline Son & 1 & & \\
\hline Presidential Candidates & 1 & & \\
\hline Sibling & 1 & & \\
\hline Total Number & 79 & Total Number & 90 \\
\hline
\end{tabular}

The domestic roles between males and females characters are similar, as presented in Table 3, 4 and 5, in which the role of husband and wife were portrayed more than other domestic roles. The most roles represented for both females and males are students and office employees, in which males portrayal of both professions outnumbers females. Males are portrayed to have occupations dealing with skills like actor, singer, and postman while occupations in the area of hospitality concierge and market vendor belongs to woman.

\section{DISCUSSION}

There are several observations that can be drawn from the research findings. First of all, males and females are equitably represented in both textbooks. There is relatively equitable numbers of occurrence of both genders in illustrations as well as in dialogues, relatively equitable proportion of male/female utterances, turns in single-gender dialogues and in mixed-gender dialogues. While male characters are slightly represented more in terms of frequency in illustrations and dialogues and number of turns in singlegender dialogues, female characters are represented more in terms of turns in mixedgender dialogues. Meanwhile, in terms of the overall number of utterances, both males and females are equitably represented. Thus, in terms of occurrence percentage, both genders are equitably represented.

Secondly, there is a deliberate attempt made by the government to equitably represent females and males in the textbooks. This attempt can be observed through the equal proportion of numbers of males and females in mixed gender illustrations. In the case where females and males are present in the single frame, the number is equally distributed. For example, in the textbook for Grade 10, picture 2.18, in a classroom setting showing students doing a classroom activity, the number of males and female students are equal. In another case like the number of character indicating balloon for a dialogue in the same page, the numbers of male and females are also equal.

Third observation from the finding is that there unequal representation in the way the characters are portrayed. In terms of occupational roles, females are associated with more hospitality-oriented jobs such as concierge, market vendor and shop assistant. On the other hand, males are portrayed to have occupational roles that show more skills like 
fisherman, seaman, and postman. In addition, there is only one male teacher as opposed to three female teachers. This is inline with Yang's (2011) research finding in Hongkong textbooks, in which among 24 characters of teachers, none of them is male. Yi's (2002) study in Blumberg (2009) also revealed similar condition English textbooks in China, where all teachers illustrated in the text are females.

The disparity of portrayal also can be observed from how males and females are presented in a mixed gender illustration. In a frame showing five Indonesian students, two females dressed in regular secondary school uniform, while one male student dresses in a boy-scout uniform, one male student in a sport wear uniform and one in regular secondary school uniform. Another example is in the classroom setting, while the composition of gender is equitable, a male student is portrayed to be the one assuming more active role as giving presentation. This is similar with the previous research on various textbooks in Indonesia done by Utomo et al. (2008). They reveal that the depiction of female occupational roles is regularly found in school textbooks. One of the examples is the portrayal of man as an expert or giving a speech, for instance as an expert giving talks on telecommunication. This kind of gender inequality in which one gender is presented to be more powerful and has a greater occupational ranges is what is called as subordination by Sunderland (2000). A similar finding of subordination was also found in Xiaoping's (2004) analysis in English textbooks in China. It was revealed that subordination existed and permeated in the textbooks in which males' occupational roles and identity are more clearly mentioned than that of females. As cited in Porecca (1984), and Schmitz (1984) in Sunderland (2001), males tend to hold more powerful occupational roles than did females in their study in classroom settings.

Finally, for the occupations that display leadership roles, females tend to be under-represented. Roles that display more authority and confidence could also be observed from the range of occupational roles and activities. In the textbooks, while there are eight politicians who are also national heroes, none of them is female. Regarding to the fact that there are numbers of heroines and a female politician who made it as a president in Indonesia, the exclusion of female politician does not represent reality. This subtle bias is also found in the study conducted by Utomo et al. (2008). In the aspect of social leadership, females are under-represented in which in social sciences textbooks, no female national heroes, except one Papuan environmentalist, was found. Males characters dominate the illustration and texts, despite the facts that the growing number of emerging Indonesian female leaders who receive international acknowledgement. Cameron (2007) stated that the stereotyping of males and females in public speaking and leadership skills, do not represent society; instead it reinforces attitude and tendency of continuing difficulty for females to assume the position of power.

The results of the study show that while there is an equitable number of a gender representation in English language textbooks in Indonesia, gender bias in favor of males can be found. This indicates the possibility of misconception that gender equity is the same as gender equality. Thus, more studies to explore how this concept permeates in educational settings are needed.

The study limits in the way that it does not explore how the texts affects students and teachers belief. Thus, future researches that explore how gender representation in English language textbooks in Indonesia affect students' and teachers' belief and behavior could provide broader and deeper understanding on this issue. 
The implication of this study is to raise awareness of the difference of gender equity and gender equality. So that teachers and students can be not affected by the values subconsciously promoted through textbooks. More awareness and critical thinking should be promoted through textbooks. As mentioned by Sunderland et al (2001), it is important to train language teachers to be ore aware with gender-biased materials and how to fairly deal with it.

\section{CONCLUSION}

The important finding of this study is that there is an equitable representation of both males and females, however there is a gender bias portraying females. Males are portrayed to be more authoritative and put in the spotlight, such as the one of doing the networking in business meeting while female characters are in the background, doing presentation, giving speech, more representative in politics, in which females are absent on this spotlight.

While deliberate effort in providing equal percentage of representation is important and already uphold, it is also important to draw our attention ontoequality in representation. This representation in terms of range of activity may also contribute in promoting societal values for both genders. Thus, it is necessary that material evaluation also take a closer look on this point to more fairly promote societal values.

It is also important that teachers should be more aware of the values that are brought in the textbook so that they can be more conscious in giving equal learning opportunity towards students.

\section{REFERENCES}

ACDP Indonesia. Policy Brief. (2013). Education Sector Analytical and Capacity Development Partnership.

Ariyanto, S. (2018). A portrait of gender bias in the prescribed Indonesian ELT textbook for junior high school students. Sexuality \& Culture, 1-23.

Blumberg, R. L. (2008). The invisible obstacle to educational equality: Gender bias in textbooks. Prospects, 38( 3), 345-361.

Cameron, D. (2005). Language, gender, and sexuality: Current issues and new directions. Applied Linguistics, 26 (4), 482-502.

Cameron, D. (2007). The Myth of Mars and Venus. Oxford: Oxford University Press.

Lakoff, R. T. (1972). Language and Woman's Place. University of Michigan: Center for Advance Study in the Behavioral Sciences.

Law, K.W.K., \& Chan, A.H.N. (2004). Gender role stereotyping in Hong Kong's primary school Chinese language subject textbooks. Asian Journal of Women's Studies, 10(1), 49-69.

Mineshima, M. (2008). Gender representations in an EFL Textbook. Bulletin of Niigata Institute of Technology, 13. Niigata Institute of Technology: Kashiwazaki City, JP.

Mukundan, J., \&Nimehchisalem, V. (2008). Gender representation in Malaysian secondary school English language textbooks. Indonesian Journal of English Language Teaching, 4(2), 155-173. 
Persell, C. H., James, C., Kang, T., \& Snyder, K. (2006). Gender and education in global perspective. In Handbook of The Sociology of Gender (pp. 407-440). Springer US.

Rifkin, B. (1998). Gender representation in foreign language textbooks: A case study of textbooks of Russian. The Modern Language Journal, 82(2), 217-236.

Setyono, B. (2018). The Portrayal of Women in Nationally-Endorsed English as a Foreign Language (EFL) Textbooks for Senior High School Students in Indonesia. Sexuality \& Culture, 1-17.

Shehadeh, A. (1999). Gender differences and equal opportunities in the ESL classroom. ELT Journal, 53(4), 256-261.

Shehadeh, A. 1994. 'Gender differences and second language acquisition'. Research Journal of Aleppo University (Arts and Humanities Series), 26, 73-98.

Sunderland, J. (2000). New understandings of gender and language classroom research: Texts, teacher talk and student talk. Language Teaching Research, 4 (2), 149-173.

Sunderland, J. (2006). Language and Gender. New York: Routledge.

Sunderland, J., Cowley, M., Abdul Rahim, F., Leontzakou, C., \& Shattuck, J. (2000). From bias "in the text" to "teacher talk around the text": An exploration of teacher discourse and gendered foreign language textbook texts. Linguistics and Education, 11(3), 251-286.

Sunderland, J., Cowley, M., Abdul Rahim, F., Leontzakou, C., \& Shattuck, J. (2001). From bias "in the text" to "teacher talk around the text" an exploration of teacher discourse and gendered foreign language textbook texts. Linguistics and education $11(3), 251-286$.

Utomo, I. D., McDonald, P., Hull, T., Rosyidah, I., Hartimah, T., Idrus, N. I., ...\&Makruf, J. (2007). Gender depiction in Indonesian school text books: progress or deterioration. In XXVI IUSSP International Population Conference, Marrakech, Morocco, September. Darisman, M. et al.

Xiaoping, Y. (2004). Gender Representation in Textbooks: A Case Study of Three English Reading Textbooks. Journal of Southeast Asian Education, 5(1) pp. 85-93.

Yang, C. C. R. (2011). Gender representation in a Hong Kong primary English textbook series: the relationship between language planning and social policy. Current Issues in Language Planning. 12 (1), 77-88. 